\title{
MICROBIOTA Y DISBIOSIS VAGINAL
} (MICROBIOTA AND VAGINAL DYSBIOSIS)

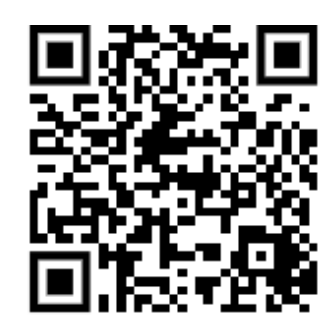

${ }^{1}$ Médico general, graduada de la Universidad Ciencias Médicas (UCIMED), médico investigadora independiente, Heredia, Costa Rica.

Código médico: 14657 Sofimo2291@gmail.com
'Dra. Sofía de los Ángeles Mora Agüero Investigadora independiente, Heredia, Costa Rica sofimo2291@gmail.com (1) https://orcid.org/0000-0001-5032-6760

RECIBIDO $10 / 12 / 2018$ CORREGIDO ACEPTADO $17 / 12 / 2018$ $21 / 12 / 2018$

\section{RESUMEN}

El cuerpo humano está colonizado por una gran cantidad de microbios, los cuales de manera colectiva se les llama microbiota humana. La relación entre ellos y la salud humana ha sido de gran estudio en los últimos años.

A nivel vaginal, la presencia de estos microorganismos se ha correlacionado con el mantenimiento de un ecosistema vaginal dinámico y propio de prevenir la colonización e infección por organismos patógenos oportunistas. El $\mathrm{pH}$ vaginal estable de las mujeres en etapa reproductiva se mantiene gracias a los estrógenos, el glucógeno y los lactobacilos, debido a su producto de ácido láctico.

Dichos lactobacilos favorecen la respuesta inmunitaria y combaten la colonización del epitelio periureteral por uropatógenos.

Este ecosistema vaginal se puede alterar por diversos mecanismos intrínsecos del húesped o por factores externos como la ingesta de antibióticos, prácticas intravaginales, alimentación o tabaco.

La importancia de mantener un ecosistema vaginal estable radica en evitar las infecciones vaginales y sus eventuales complicaciones.

PALABRAS CLAVES: Microbiota, Lactobacillus, disbiosis, vaginosis bacteriana

\section{ABSTRACT}

The human body is colonized by a large number of microbes which are collectively called human microbiota. The relationship between them and human health has been a great study in recent years.

At the vaginal level, the presence of these microorganisms has been correlated with the maintenance of a dynamic vaginal ecosystem and proper to prevent colonization and infection by opportunistic pathogens. The stable vaginal $\mathrm{pH}$ of women in the reproductive stage is maintained thanks to estrogen, glycogen and lactobacilli, due to its lactic acid product. 
Said lactobacilli favor the immune response and combat the colonization of the periureteral epithelium by uropathogens.

This vaginal ecosystem can be altered by various intrinsic mechanisms of the host or by external factors such as the intake of antibiotics, intravaginal practices, food or snuff.

The importance of maintaining a stable vaginal ecosystem lies in avoiding vaginal infections and their possible complications.

KEYWORDS: Microbiota, Lactobacillus, dysbiosis, vaginosis, bacterial.

\section{INTRODUCCIÓN}

El cuerpo humano cuenta con más de 100 trillones de microorganismos simbióticos, estos son bacterias que forman parte de su ecología, tienen influencia importante en el desarrollo, fisiología, inmunidad y nutrición.

Las comunidades microbianas se denominan microbiota y su material genético se denomina microbioma, ambas difieren según el sitio del cuerpo en que se ecuentren. La microbiota humana coloniza la piel, cavidad oral, conjuntivas, tracto respiratorio, tracto gastrointestinal, vagina, entre otros (1, 2).

\section{MATERIALES Y MÉTODOS}

Para la elaboración de esta revisión, se buscó bibliografía en Pubmed con los términos "microbiota humana", "microbiota vaginal" y "disbiosis vaginal". La búsqueda se enfocó en asociar dichos temas. Sólo se tomaron en cuenta artículos que se encontraban en inglés o español.

Una vez clasificada la información, se redactó el siguiente artículo de revisión.

\section{GENERALIDADES}

La vagina es una estructura fibromuscular, que cuenta con tres capas histológicas: mucosa, muscular y adventicia. En la vagina se albergan microorganismos generando un estatus fisiológico, el cual es importante para el bienestar reproductivo de la huesped. La composición de la microbiota vaginal es dinámica y responde a los distintos estados hormonales que atraviesa la mujer en su vida reproductiva $(3,4)$. La presencia de ácido láctico tiene un papel importante y su producción proviene de dos fuentes distintas, por parte del epitelio vaginal y por parte de la microbiota. La primera es mediante el lumen vaginal, el cual está compuesto por epitelio escamoso estratificado no queratinizado que carece de glándulas, pero gracias a la difusión del flujo sanguíneo, se provee de glucosa y nutrientes esenciales para el medio vaginal. Es un epitelio metabólicamente activo ya que transiciona desde la proliferación, la maduración y la descamación a nivel del lumen vaginal. Cuando se requiere energía en forma de ATP, el glucógeno en las células epiteliales vaginales es convertido en glucosa y posteriormente en piruvato, 
para finalmente generar ácido láctico, el cual se va liberando al lumen vaginal conforme el epitelio se descama $(4,5)$.

Esta producción de ácido láctico se encuentra bajo el control de los niveles de estrógenos presentes en sangre, ya que promueven la maduración y el depósito del mismo en las células epiteliales vaginales. Por lo tanto, debido al cambio de estrógenos a lo largo de la vida de la mujer, el ecosistema vaginal se modifica (5).

El segundo y principal mecanismo productor de ácido láctico corresponde al glucógeno que se encuentra en el lumen vaginal, el cual es catabolizado por la alfa amilasa para producir maltosa, maltotriosa y alfa dextrinas, posteriormente convirtiéndose en ácido láctico, gracias a la acción de la deshidrogenasa láctica estimulada por los lactobacilos $(3,5)$.

\section{MECANISMO DE LOS LACTOBACILOS}

Los Lactobacillus spp. son bacterias anaerobicas tipo grampositivo, que generan catabolismo del glucógeno fermentativo produciendo, predominantemente, ácido láctico. Esta condición contribuye a que el pH de la vagina se mantenga ácido en niveles de aproximadamente $3.5-4.5$, lo cual genera un ambiente de protección en la mucosa manteniendo, parcial o totalmente inhibido el creciminento de microorganismos patógenos $(6,7)$.

Se han descrito cinco distintos tipos de condición comunitaria (CST, por sus siglas en inglés): I, II, III, y V, las cuales se rigen por Lactobacillus crispatus, Lactobacillus gaseri, Lactobacillus iners, y Lactobacillus jensenii, respectivamente, y el IV se caracteriza, no por predominancia de lactobacilos, sino por una combinación polimicrobiana de anaerobios estrictos y facultativos como Gardnerella, Atopobium, Mobiluncus, y Prevotella $(8,9)$.

Se ha identificado que la frecuencia de estas difiere según grupos étnicos, siendo la CST IV, la más común (aproximadamente 40\%) en mujeres hispánicas y de raza negra (9).

La presencia de lactobacilos que predomina a nivel vaginal, tiene la capacidad de colonizar y proteger la capa mucosa e impedir el establecimiento o desarrollo excesivo de microorganismos que son potecialmente patógenos, mediante dos mecanismos:

\section{1) Adherencia específica de la} microbiota a las células epiteliales

Existe reconocimiento, aún en estudio, entre los lactobacilos y receptores a nivel epitelial. Se ha descrito la capacidad, por parte de dichos microorganismos, de autoagregarse $y$ adherirse al epitelio vaginal. Por ejemplo, la presencia de la fibronectina, la cual es una glucoproteína que cubre la superficie de las células epiteliales, cumple con la función adhesiva, le permite a la flora vaginal adherirse a la mucosa, lo cual se ve favorecido a niveles de $\mathrm{pH} 4$ versus $\mathrm{pH} 8$ (10).

También se asocian otros componentes en la superficie bacterial celular que permite la adherencia de los microorganismos, como lo son proteínas, carbohidratos, otras glucoproteínas, ácidos lipoteicoicos y cationes divalentes. Sin embargo, esta diversidad de adherencia por parte de las cubiertas bacterianas aún requiere más estudios. (11) 


\section{2) Compuestos antimicrobianos producidos por los lactobacilos}

\section{- Ácido láctico}

La vagina es un órgano que carece de glándulas, por lo que la superficie de la misma se encuentra lubricada por una capa de líquido, formada gracias al trasudado del plasma sanguíneo proveniente de los capilares de la lámina propia. La composición de este trasudado difiere del plasma en cuanto a las concentraciones de $\mathrm{Na}+, \mathrm{K}+, \mathrm{Cl}-\mathrm{y}$ $\mathrm{H}+$. Se ha estudiado que el acidez del ambiente vaginal también proviene del bombeo de protones por parte de una $\mathrm{H}+$-ATPasa de la membrana apical en las células vaginales (12).

Sin embargo, se encuentra un mayor respaldo científico del pH ácido debido al alto depósito de glucógeno epitelial y su metabolismo. También se ha reportado la presencia, pero en menor cantidad, de ácido acético.

El ácido láctico producido, se presenta en dos isómeros: $\mathrm{L}$ - lactato y $\mathrm{D}$ - lactato.

El epitelio vaginal per se, produce aproximadamente el $20 \%$ del total de ácido láctico, siendo este en su mayoría la forma L- lactato. Por otro lado, la microbiota metaboliza alrededor del $80 \%$ del glucógeno, produciendo las dos isoformas de ácido láctico con predominancia del D- ácido láctico (9, 13).

Ambos productos del metabolismo de glucosa ocurren en el ambiente anaeróbico vaginal. El L-ácido láctico puede ser transportado, mediante mecanismos al interior de las células epiteliales, esto gracias a un inductor de metaloproteinasa extracelular (EMMPRIN), el cual es una proteína presente en las membranas celulares del húesped y un cofactor esencial para el transportador de proteína monocarboxilada 1 (MCT-1), este se encarga de regular los niveles de ácido láctico intracelular. Una regulación a la alta del EMMPRIN y de MCT-1, protege a las células de un exceso de ácido láctico, manteniendo un $\mathrm{pH}$ intracelular funcional (8).

También, se ha determinado que según la CST presente, así va a ser la proporción producida de D- o L- ácido láctico $(8,9)$.

Estudios recientes indican que el ácido láctico puede influir directamente en la función inmune del huésped, inhibiendo respuestas proinflamatorias y estimulando la respuesta antiviral $(5,9)$.

\section{- Peróxido de hidrógeno}

Se ha estudiado que el ambiente cervicovaginal es microaeróbio (hipóxico), lo que significa que los niveles de oxígeno se encuentran en rangos de 15 a $35 \mathrm{mmHg}$, esto corresponde aproximadamente el $2 \%$ de los niveles atmosféricos (14).

Los lactobacilos vaginales son anaerobios aerotolerantes y algunos producen peróxido de hidrógeno (H2O2). Ciertas especies de lactobacilos tienen la capacidad de producir $\mathrm{H} 2 \mathrm{O} 2$. Las cepas que producen $\mathrm{H} 2 \mathrm{O} 2$ son más estables en el ambiente vaginal y protegen mejor la mucosa frente a alteraciones causadas por microorganismos oportunistas, incluyendo los productores de infecciones de transmisión sexual. El efecto bactericida del $\mathrm{H} 2 \mathrm{O} 2$ se detremina por su capacidad oxidante. Sin embargo, a pesar de estos datos, se determina que el control de la flora vaginal por lactobacilos es complejo, y el 
peróxido de hidrógeno es parte de este mecanismo sin ser el principal $(6,15)$.

\section{- Bacteriocinas}

Estos son polipéptidos con actividad antimicrobiana producidos por bacterias, sintetizadas a nivel ribosomal, estas biosustancias mantienen una actividad antimicrobial. Ahora bien, la actividad antagonista clara no se conoce, ya que su función bactericida solo se ha comprobado in vitro $(6,16)$.

\section{DISBIOSIS VAGINAL}

En ocasiones las concentraciones de lactobacilos se modifican, produciendose una disbiosis de la microbiota vaginal, lo que se define como una condición polimicrobiana caracterizada por baja presencia de Lactobacillus y sobrecrecimiento de anaerobeos. La disbiosis más común se presenta como vaginosis bacteriana. Esta condición se caracteriza por presentar tres alteraciones en el ambiente vaginal (17, 19):

1. Cambio en la flora vaginal de Lactobacillus a anaerobios facultativos.

2. Producción de aminos volátiles por parte de la nueva flora bacteriana.

3. Aumento del $\mathrm{pH}$ vaginal a más de 4.5.

Estas condiciones favorecen a que microorganismos oportunistas se desarrollen comportándose como patógenos, ya sea que estos se encuentren de manera habitual en la vagina o que provengan exógenamente (6).
Existen una serie de factores que influyen en la variación del microbioma vaginal que se explican a continuación:

\section{- Actividad sexual}

La conducta sexual relacionada con múltiples parejas y la falta de utilización del condón, se asocia con mayor diversidad de microbiota vaginal y con disminución de lactobacilos. También se reportan citoquinas inflamatorias elevadas en mujeres con vaginosis bacteriana, lo cual a su vez se relaciona con la presencia de microorganismos causantes de infecciones de transmisión sexual, como Chlamydia trachomatis, Neisseria gonorrhoeae, virus Herpex Simplex tipo 2, Trichomonas vaginalis y vaginosis bacteriana $(18,20)$.

\section{- Raza o grupo étnico}

La prevalencia de la vaginosis bacteriana varía según el grupo etnico, la razón de las diferencias no se conoce aún, pero se especula que podría ser debido a que la composicion de las especies de comunidades vaginales están gobernadas por diferencias genéticas determinadas por los húespedes $(6,21$, 22).

\section{- Edad y fisiología hormonal}

Los efectos de las hormonas sexuales, en especial de los estrógenos, se manifiesta mediante el favorecimiento del glucógeno en la mucosa vaginal lo cual contribuye en la predominancia de Lactobacillus spp y en la estabilidad de la microbiota.

La composición de la microbiota vaginal cambia a través del tiempo. Está bien establecido que la fisiología vaginal se modifica no solo debido a la producción y concentración de estrógenos, sino 
también a la composición de la microbiota vaginal.

Durante el embarazo, el feto crece estéril, la primera colonización se da en el momento del parto, la cual proviene de la vagina o de la piel, según sea la vía del parto. En el recién nacido, la vulva y vagina del infante se ven influenciadas por la presencia de residuos estrogénicos transplacetarios, estos favorecen el aporte de glucógeno y es metabolizado por las bacterias endógenas disminuyendo el $\mathrm{pH}$ vaginal, conforme estos estrógenos se metabolizan, se pierde el contenido de glucógeno vaginal y el $\mathrm{pH}$ se neutraliza o alcaliniza (23).

Con respecto a la infancia, se ha determinado que el $\mathrm{pH}$ vaginal se mantiene neutro 0 alcalino, con colonización de difteroides (Corynebacterium spp. 78\%), Staphylococcus epidermidis (73\%) y mycoplasma (24).

Durante la puertad, debido a la maduración de las glándulas adrenales y las gónadas, los estrógenos comienzan a elevarse y empieza a aumentar la producción de glúcógeno intracelular. Se han determinado dos colonias predominantes en esta etapa de la vida: Lactobacillus spp. y bacterias alternas productoras de ácido láctico (Atopobium y Streptococcus spp.) (24).

El ambiente vaginal en las mujeres en etapa reproductiva, varía durante el ciclo menstrual debido a las fluctuaciones hormonales, influyendo en el grosor del epitelio vaginal y en la disponibilidad de glucógeno. Durante la menstruación, al encontrarse disminuidos los niveles de estrógenos, consecuentemente el $\mathrm{pH}$ se altera, siendo próximo a la neutralidad y se dificulta el crecimiento de los lactobacilos. El uso de anticoncepción hormonal se ha asociado con la disminución de riesgo de presentar vaginosis bacteriana, debido a que genera una mayor estabilidad estrogénica $(6,24,25,26)$.

Posteriormente conforme los estrógenos disminuyen hasta llegar a la menopausia, las dominancia de Lactobacillus decrece y se estabiliza (3).

Las mujeres postmenopáusicas en consecuencia al descenso de los estrógenos y su efecto, el pH vaginal incrementa, pasando a predominar bacterias entéricas (27).

\section{- Estilo de vida}

La respuesta fisiológica al estrés psicosocial mediante el sistema de "lucha o ida", es a través de la producción de cortisol, hormona esteroidea que aparenta alterar la respuesta inmunológica e inhibir el depósito de glucógeno vaginal. Existen prácticas diarias que pueden influenciar en el grado de acidez vaginal, lo que predispone de manera importante a la proliferación excesiva de patógenos oportunistas $(27,28)$.

\section{- Prácticas locales}

La aplicación de productos de higiene femenina o las duchas vaginales, pueden alterar la barrera inmune vaginal, teniendo efecto sobre la integridad celular (27). El uso de tampones podría no tener un efecto importante sobre el $\mathrm{pH}$ vaginal, sin embargo por períodos prolongados, puede elevarlo siendo contraproducente para la ambiente vaginal. La alcalinidad de la 
menstruación o del semen neutraliza el $\mathrm{pH}$ vaginal temporalmente $(6,29,30)$.

- Prácticas sistémicas

El uso de antibióticos permea el exudado vaginal, provocando alteración en el ecosistema de la vagina.

El fumar cigarrillo, también se asocia con la vaginosis bacteriana, debido a la presencia de nicotina y su metabolito cotinina en el moco cervical de mujeres fumadoras.

La condición se relaciona con diversos mecanismos expuestos: cambios fisiológicos y estructurales, aumento de la virulencia bacteriana, alteración en la regulación de la función inmune, acumulación vaginal de compuestos aminos, y al efecto antiestrogénico del cigarrillo $(22,31)$.

En cuanto a la alimentación, se propone que el aumento en el consumo de grasas saturadas aumenta la incidencia de vaginosis bacteriana, la consecuencia más frecuente de la disbiosis vaginal, y por otro lado el consumo de folato, vitamina $\mathrm{E}$ y calcio disminuye el riesgo de vaginosis bacteriana.

En cuanto a las mujeres embarazadas las deficiencias subclínicas de hierro y vitamina $D$, se han visto asociadas a un incremento en el riesgo de vaginosis bacteriana $(19,22,32)$.

\section{COMPLICACIONES DE LA DISBIOSIS VAGINAL}

La alteración en la microbiota vaginal puede desencadenar labor pretérmino del embarazo, infecciones maternas o neonatales, enfermedad pélvica inflamatoria o infección por el virus de inmunodeficiencia humana $(33,35)$.

\section{- Parto pretérmino}

El parto pretérmino tiene una prevalencia elevada, siendo una causante de muerte neonatal importante.

La relación con la presencia de infección en el líquido amniótico puede culminar en parto pretérmino.

La primera razón de infección es debida al ascenso de bacterias desde el tracto genital inferior (33).

\section{- Infecciones maternas o neonatales}

La salud materna se refiere al periodo de embarazo, a la etapa postparto o postaborto.

Se determina una relación entre la muerte materna y la presencia de infecciones, lo que no esta claro es si el origen de la infección es vaginal o ambiental. En cuanto al neonato (considerado desde el momento en que nace hasta cumplir 3 meses de vida), la infección más estudiada ha sido la causada por el $\mathrm{S}$. agalactiae que se puede encontrar en el canal vaginal (34).

\section{- Enfermedad pélvica inflamatoria}

La enfermedad pélvica inflamatoria consiste en una infección aguda del tracto genital femenino superior, a causa de infecciones de transmisión sexual. Existe cierta duda en cuanto a la relación entre la vaginosis bacteriana como causante de le enfermedad pélica inflamatoria. Sin embargo, se ha visto que la adquisición de infecciones de transmisión sexual se influencia según la comunidad bacteriana dominante en el ambiente vaginal $(7,22)$.

\section{- Infección por Virus de Inmunodeficiencia Humana}

Existe una relación considerable entre la disbiosis vaginal y un riesgo aumentado 
en la adquisición y transmisión de Virus de Inmunodeficiencia Humana 1. Por ejemplo, se asocia particularmente la presencia de L. crispatus en el moco cervical con una replicación disminuida del virus de inmunodeficiencia humana 1 , aparentemente debido a un aumento de los niveles de D- ácido láctico en el moco cervical (22).

\section{CONCLUSIONES}

La microbiota a nivel del cuerpo humano tiene un papel importante que aún esta en investigación. En el caso del sistema genital femenino predomina la presencia de Lactobacilos spp., que mediante distintos mecanismos producen un ambiente de defensa ante patógenos oportunistas. Existen factores, tanto modificables como no modificables. Los últimos, es necesario tomarlos en cuenta para mejorar el ambiente vaginal.

Debido a esto es importante dar a conocer los variables modificables, lo cual podría prevenir complicaciones en la salud de mujeres en edad reproductiva y en estado de embarazo.

\section{REFERENCIAS}

1. Wang B, Yao M, Lv L, Ling Z, Li L. The Human Microbiota in Health and Disease. Engineering. 2017 02;3(1):71-82. https://doi.org/10.1016/j.eng.2017.01.008

2. Stoyancheva G, Marzotto M, Dellaglio F, Torriani S. Bacteriocin production and gene sequencing analysis from vaginal Lactobacillus strains. Archives of Microbiology. 201406 12;196(9):645-653. https://doi.org/10.1007/s00203-014-1003-1

3. Amabebe E, Anumba DOC. The Vaginal Microenvironment: The Physiologic Role of Lactobacilli. Frontiers in Medicine. 201806 13;5. https://doi.org/10.3389/fmed.2018.00181

4. Gartner L, Hiatt J. Texto Atlas de Histología. 3 ed.. McGraw-Hill; 2008.

5. Mossop H, Linhares IM, Bongiovanni AM, Ledger WJ, Witkin SS. Influence of Lactic Acid on Endogenous and Viral RNA-Induced Immune Mediator Production by Vaginal Epithelial Cells. Obstetrics \& Gynecology. $2011 \quad$ Oct;118(4):840-846. https://doi.org/10.1097/aog.0b013e31822da9e9

6. Martín R, Soberón N, Vázquez F, Suárez JE. La microbiota vaginal: composición, papel protector, patología asociada y perspectivas terapéuticas. Enfermedades Infecciosas y Microbiología Clínica. 2008 03;26(3):160-167. https://doi.org/10.1157/13116753

7. Lewis FMT, Bernstein KT, Aral SO. Vaginal Microbiome and Its Relationship to Behavior, Sexual Health, and Sexually Transmitted Diseases. Obstetrics \& Gynecology. 2017 04;129(4):643-654. https://doi.org/10.1097/aog.0000000000001932

8. Witkin SS, Mendes-Soares H, Linhares IM, Jayaram A, Ledger WJ, Forney LJ. Influence of Vaginal Bacteria and D- and L-Lactic Acid Isomers on Vaginal Extracellular Matrix Metalloproteinase Inducer: Implications for Protection against Upper Genital Tract Infections. mBio. 201308 06;4(4). https://doi.org/10.1128/mbio.00460-13 
9. Smith SB, Ravel J. The vaginal microbiota, host defence and reproductive physiology. The Journal of Physiology. 201605 05;595(2):451-463. https://doi.org/10.1113/jp271694

10. Nagy E, FROMan G, MARDH P. Fibronectin binding of Lactobacillus species isolated from women with and without bacterial vaginosis. Journal of Medical Microbiology. 199207 01;37(1):38-42. https://doi.org/10.1099/00222615-37-1-38

11. Boris S, Suárez JE, Vázquez F, Barbés C. Adherence of Human Vaginal Lactobacilli to Vaginal Epithelial Cells and Interaction with Uropathogens. Infection and Immunity. 1998;66(5):19851989.

12. Mas M. Fisiología de la respuesta sexual femenina: actualización. Revista Internacional de Andrología. 2007 01;5(1):11-21. https://doi.org/10.1016/s1698-031x(07)74029-3

13. Boskey $\mathrm{E}$, Cone R, Whaley $\mathrm{K}$, Moench $\mathrm{T}$. Origins of vaginal acidity: high $\mathrm{d} / \mathrm{l}$ lactate ratio is consistent with bacteria being the primary source. Human Reproduction. 2001 09;16(9):18091813. https://doi.org/10.1093/humrep/16.9.1809

14. Tachedjian G, O'Hanlon DE, Ravel J. The implausible "in vivo" role of hydrogen peroxide as an antimicrobial factor produced by vaginal microbiota. Microbiome. 201802 06;6(1). https://doi.org/10.1186/s40168-018-0418-3

15. Strus M, Brzychczy-WÅ M, Gosiewski T, Kochan P, Heczko PB. The in vitro effect of hydrogen peroxide on vaginal microbial communities. FEMS Immunology \& Medical Microbiology. 2006 Oct;48(1):56-63. https://doi.org/10.1111/j.1574-695x.2006.00120.x

16. Borgogna JC, Yeoman CJ. The Application of Molecular Methods Towards an Understanding of the Role of the Vagina Microbiome in Health Disease. Methods in Microbiology. 2017 Jan;44:37-65. https://doi.org/10.1016/bs.mim.2017.08.003

17. Bradley F, Birse K, Hasselrot K, Noël-Romas L, Introini A, Wefer H, Seifert M, Engstrand L, Tjernlund A, Broliden K, Burgener AD. The vaginal microbiome amplifies sex hormoneassociated cyclic changes in cervicovaginal inflammation and epithelial barrier disruption. American Journal of Reproductive Immunology. 201804 30;80(1):e12863. https://doi.org/10.1111/aji.12863

18. Muhleisen AL, Herbst-Kralovetz MM. Menopause and the vaginal microbiome. Maturitas. 2016 09;91:42-50. https://doi.org/10.1016/j.maturitas.2016.05.015

19. Brotman R, Gajer P, Holm J, Robinson C, Ma B, Humphrys M, Tuddenham S, Ravel J, Ghanem K. Hormonal contraception is associated with stability and lactobacillus-dominance of the vaginal microbiota in a two-year observational study. American Journal of Obstetrics and Gynecology. 2016 Dec;215(6):S828-S829. https://doi.org/10.1016/j.ajog.2016.09.031

20. Fashemi B, Delaney ML, Onderdonk AB, Fichorova RN. Effects of feminine hygiene products on the vaginal mucosal biome. Microbial Ecology in Health \& Disease. 201302 25;24(0). https://doi.org/10.3402/mehd.v24i0.19703

21. Amabebe E, Anumba DOC. Psychosocial Stress, Cortisol Levels, and Maintenance of Vaginal Health. Frontiers in Endocrinology. 201809 24;9. https://doi.org/10.3389/fendo.2018.00568 
22. Hickey R, Abdo Z, Zhou X, Nemeth K, Hansmann M, Osborn T, Wang F, Forney L. Effects of tampons and menses on the composition and diversity of vaginal microbial communities over time. BJOG: An International Journal of Obstetrics \& Gynaecology. 201302 11;120(6):695-706. https://doi.org/10.1111/1471-0528.12151

23. Miller EA, Beasley DE, Dunn RR, Archie EA. Lactobacilli Dominance and Vaginal $\mathrm{pH}$ : Why Is the Human Vaginal Microbiome Unique?. Frontiers in Microbiology. 2016 Dec 08;7. https://doi.org/10.3389/fmicb.2016.01936

24. Brotman RM, He X, Gajer P, Fadrosh D, Sharma E, Mongodin EF, Ravel J, Glover ED, Rath JM. Association between cigarette smoking and the vaginal microbiota: a pilot study. BMC Infectious Diseases. 201408 28;14(1). https://doi.org/10.1186/1471-2334-14-471

25. Romero R, Dey SK, Fisher SJ. Preterm labor: One syndrome, many causes. Science. 201408 14;345(6198):760-765. https://doi.org/10.1126/science.1251816

26. Kenyon C, Colebunders R, Crucitti T. The global epidemiology of bacterial vaginosis: a systematic review. American Journal of Obstetrics and Gynecology. 2013 Dec;209(6):505-523. https://doi.org/10.1016/j.ajog.2013.05.006

27. Neggers YH, Nansel TR, Andrews WW, Schwebke JR, Yu K, Goldenberg RL, Klebanoff MA. Dietary Intake of Selected Nutrients Affects Bacterial Vaginosis in Women. The Journal of Nutrition. 200709 01;137(9):2128-2133. https://doi.org/10.1093/jn/137.9.2128

28. Simon C. Introduction: Do microbes in the female reproductive function matter?. Fertility and Sterility. 2018 08;110(3):325-326. https://doi.org/10.1016/j.fertnstert.2018.06.041

29. Amabebe E, Anumba DOC. Psychosocial Stress, Cortisol Levels, and Maintenance of Vaginal Health. Frontiers in Endocrinology. 201809 24;9. https://doi.org/10.3389/fendo.2018.00568

30. Hickey R, Abdo Z, Zhou X, Nemeth K, Hansmann M, Osborn T, Wang F, Forney L. Effects of tampons and menses on the composition and diversity of vaginal microbial communities over time. BJOG: An International Journal of Obstetrics \& Gynaecology. 201302 11;120(6):695-706. https://doi.org/10.1111/1471-0528.12151

31. Brotman RM, He X, Gajer P, Fadrosh D, Sharma E, Mongodin EF, Ravel J, Glover ED, Rath JM. Association between cigarette smoking and the vaginal microbiota: a pilot study. BMC Infectious Diseases. 201408 28;14(1). https://doi.org/10.1186/1471-2334-14-471

32. Neggers YH, Nansel TR, Andrews WW, Schwebke JR, Yu K, Goldenberg RL, Klebanoff MA. Dietary Intake of Selected Nutrients Affects Bacterial Vaginosis in Women. The Journal of Nutrition. 200709 01;137(9):2128-2133. https://doi.org/10.1093/jn/137.9.2128

33. Miller EA, Beasley DE, Dunn RR, Archie EA. Lactobacilli Dominance and Vaginal pH: Why Is the Human Vaginal Microbiome Unique?. Frontiers in Microbiology. 2016 Dec 08;7. https://doi.org/10.3389/fmicb.2016.01936 
34. Kenyon C, Colebunders R, Crucitti T. The global epidemiology of bacterial vaginosis: a systematic review. American Journal of Obstetrics and Gynecology. 2013 Dec;209(6):505-523. https://doi.org/10.1016/j.ajog.2013.05.006

35. Romero R, Dey SK, Fisher SJ. Preterm labor: One syndrome, many causes. Science. 201408 14;345(6198):760-765. https://doi.org/10.1126/science.1251816 